\title{
FAKTOR DOMESTIK KEBIJAKAN PEMERINTAH HUNGARIA DALAM MENANGANI PENGUNGSI DAN MIGRAN DARI TIMUR TENGAH PERIODE TAHUN 2015-2019
}

\author{
Angga Nurdin Rachmat \\ Program Studi Hubungan Internasional, Fakultas Ilmu Sosial dan Ilmu Politik \\ Universitas Jenderal Achmad Yani \\ angga.nurdin@lecture.unjani.ac.id
}

\begin{abstract}
Abstrak
Hungaria telah menjadi negara pihak dalam Konvensi 1951 dan Protokol 1967 tentang Pengungsi yang mengharuskan mematuhi prinsip non-refoulment terhadap para pengungsi dan migran dari Timur Tengah yang datang ke negaranya pada tahun 2015. Namun, pada kenyataannya Hungaria menerapkan kebijakan untuk menahan dan mengembalikan para pengungsi tersebut agar tidak masuk ke negaranya bahkan dengan cara-cara represif. Kebijakan ini jelas bertentangan dengan prinsip perlindungan terhadap pengungsi serta kebijakan Uni Eropa (UE) dimana Hungaria menjadi anggota didalamnya. Kebijakan yang diambil oleh Hungaria tidak dapat dilepaskan dari faktor domestik yang memengaruhi pilihan pemerintah Hungaria mengambil kebijakan yang bertentangan dengan Konvensi yang mengikatnya serta kebijakan UE. Oleh karena itu tulisan ini berupaya untuk menjawab apa saja faktor domestik yang memengaruhi kebijakan Hungaria dalam menangani pengungsi dan migran dari Timur Tengah periode 2015-2019, dengan menggunakan metode kualitatif berdasarkan sumber data yang diperoleh dari studi kepustakaan mengenai berbagai aspek dalam politik domestik Hungaria. Argumen dalam penelitian ini adalah kebijakan Hungaria terhadap para pengungsi dan migran dipengaruhi oleh faktor domestik yang terkait dengan kepentingan elit sebagai strategi memenangkan pertarungan politik didalam negeri yang terkait dengan gagaasn identitas nasional Viktor Orban sebagai Perdana Menteri Hungaria sekaligus pemimpin partai berkuasa,Fidesz.
\end{abstract}

Kata kunci: politik domestik, Viktor Orban, Identitas, Populisme, Fidesz.

\begin{abstract}
Hungary has become a party to the 1951 Convention and 1967 Protocol on Refugees which obliges to comply with the principle of non-refoulment towards refugees and migrants from the Middle East who came to their country in 2015. However, in reality Hungary has implemented a policy of detaining and returning these refugees. Soas not to enter the country even by repressive means. This policy is clearly contrary to the principle of protection against refugees and the policies of the European Union (EU) in which Hungary is a member. The policies taken by
\end{abstract}


Hungary cannot be separated from domestic factors that influence the choice of the Hungarian government to take policies that are contrary to the binding Convention and EU policy. Therefore this paper seeks to answer what are the domestic factors that influenced Hungarian policies in dealing with refugees and migrants from the Middle East for the period 2015-2019, using qualitative methods based on data sources obtained from literature studies on various aspects of Hungarian domestic politics. The argument in this research is that Hungary's policy towards refugees and migrants is influenced by domestic factors related to elite interests as a strategy to win the political battle in the country related to the gaga of national identity of Viktor Orban as the Prime Minister of Hungary and leader of the ruling party, Fidesz.

Keywords: Domectic Politics, Viktor Orban, Identity, Populism, Fidesz.

\section{PENDAHULUAN.}

Pengungsi menjadi fokus perhatian sejak terjadinya Perang Dunia II, dimana warga sipil meninggalkan negaranya untuk menghindari perang dan mencari perlindungan di negara atau wilayah lain. Perhatian masyarakat Internasional terhadap jaminan atas hak dari pengungsi terwujud melalui Konvensi tahun 1951 serta protokol tambahan tahun 1967.Secara garis besar Konvensi tersebut memberikan penjelasan mengenai definisi pengungsi serta standar dasar dalam memerlakukan para pengungsi. Melalui Konvensi ini, negara pihak harus mematuhi segala kewajiban untuk menjalankan tanggungjawab untuk memberikan perlindungan kepada pengungsi, dimana secara hukum status yang disandang oleh pengungsi tersebut menjadikan negara harus mematuhi prinsip non-refoulement ${ }^{1}$ yang hingga saat ini masih diakui sebagai praktek hukum kebiasaan internasional (Sainz-Pardo, 2002: 30). Disamping itu hal krusial lainnya adalah perlindungan minimum yang diberikan kepada pengungsi berdasarkan alasan kemanusiaan, dimana salah satu hal penting adalah bahwa pengungsi akan mendapatkan jaminan atas hak-hak dasar serta kebebasannya sebagaimana yang tercantum dalam United Nations Declaration of Human Right.

\footnotetext{
${ }^{1}$ Refoulement berasal dari bahasa Perancis yang Refouler yang memiliki arti mengembalikan atau mengirim balik, artinya dalam Prinsip Non-Refoulement adalah larangan bagi negara untuk menolak atau mengusir atau mengembalikan pengungsi yang datang ke negaranya ke wilayah perbatasan Negara Pihak yang akan mengancam kehidupan maupun kebebasan pengungsi karena perbedaan ras, agama, kebangsaan, keanggotaan pada kelompok sosial tertentu ataupun karenan pandangan politiknya seperti yang tercantum dalam Pasal 33 Konvensi Pengungsi 1951.
} 
Berdasarkan catatan United Nations High Commissioner for Regugees (UNHCR) per April 2015 terdapat 142 Negara yang menjadi pihak pada Konvensi 1951 dan Protokol 1967 dan Hungaria telah melakukan aksesi baik Konvensi dan Protokol tersebut pada 14 Maret 1989 (UNHCR, 2015: 3). Dengan demikian Hungaria telah menjadi negara pihak dalam Konvensi 1951 dan Protokol 1967 yang terikat dengan hak dan kewajiban terkait dengan permasalahan pengungsi. Bergabungnya Hungaria sebagai negara pihak dalam konvensi 1951 dan protokol 1967, pemerintah Hungaria membentuk sebuah badan khusus yakni Office for Refugee Affairs yang didanai oleh UNHCR. Badan ini bertujuan untuk memberikan pertimbangan terkait dengan aplikasi untuk memberikan status pengungsi politik (Szoke, 1992: 308). Pembentukan badan tersebut menunjukan komitmen Hungaria dalam usaha untuk melaksanakan kewajiban sebagai negara pihak dalam konvensi 1951 dan protokol 1967 serta terbuka terhadap migrasi sebagai upaya mengintegrasikan diri dengan Uni Eropa dikemudian hari.

Komitmen Hungaria terhadap isu pengungsi dan migran kemudian diuji saat Eropa menghadapi krisis pengungsi dan migran yang berasal dari Timur Tengah pada tahun 2015. Krisis pengungsi ini muncul seiring dengan konflik dan instabilitas yang terjadi di wilayah tersebut akibat konflik yang berlarut-larut khususnya di Suriah. Uni Eropa sebagai institusi kawasan kemudian merespon dengan membuat kebijakan pembagian kuota relokasi pengungsi dan migran ke negara-negara anggotanya. Hungaria bersama dengan Polandia, Republik Ceko dan Slovakia yang tergabung dalam Visegard 4 (V4) secara tegas menolak kebijakan yang dikeluarkan oleh Komisi Eropa (Karolewski dan Benedikter, 2018). Hungaria bahkan membangun tembok dan pagar di wilayah perbatasan dengan Serbia untuk mencegah masuknya pengungsi dan migran asal Timur Tengah tersebut ke negaranya. Disamping itu Hungaria mengedepankan pendekatan keamanan (security approach) untuk menangani pengungsi yang tetap melintas serta telah berada di negaranya. Pendekatan keamanan ini menjadi justifikasi bagi Hungaria untuk menggunakan tindakan-tindakan represif yang bertujuan untuk mencegah masuknya para pengungsi tersebut serta menerapkan kebijakan dengan tujuan mengusir mereka dari negaranya. Kondisi tersebut pada kenyataannya 
mencerminkan Hungaria sebagai negara pihak dalam konvensi 1951 dan protokol 1967 dimana tidak melaksanakan kewajiban yang tercantum dalam Konvensi dan Protokol tersebut. Hal ini menjadi sangat ironis mengingat bahwa dalam isu ini Hungaria hanya diposisikan sebagai negara transit atau perlintasan sebelum para pengungsi ini menuju ke negara lain.

Fenomena mengenai kebijakan Hungaria terhadap permasalahan pengungsi telah menarik banyak penelitian. Hungaria menjadi negara yang memiliki daya tarik bagi pengungsi dan migran ditemukan pada penelitian Barczika dan Szent-Ivanyi (2018). Kebijakan Hungaria dari perspektif realisme dengan analisis kepentingan nasional Hungaria menjadi tema dalam tulisan Rachmat (2020). Upaya Hungaria untuk mencegah masuknya pengungsi dan migran ke negaranya dengan menggunakan politik identitas sebagai dasar kebijakan menjadi tema pada tulisan Mendelski (2019), Pradana (2018), Cantat dan Rajaram (2018). Disisi lain kajian mengenai sekuritisasi pengungsi dan migran yang dilakukan oleh Hungaria dapat dilihat pada penelitian Szalai dan Gobl (2015) dan Miholjcic (2017). Berdasarkan tulisan-tulisan yang telah ada, belum ada penelitian yang memberikan penekanan terhadap setting domestik dari Hungaria yang membentuk kebijakan represif negara tersebut terhadap pengungsi dan migran yang melintas ke negaranya dengan menggunakan pendekatan realisme neo-klasik.

Berdasarkan permasalahan serta melengkapi tulisan mengenai isu pengungsi di Hungaria tersebut, tulisan ini akan berusaha untuk menjawab pertanyaan bagaimana level-domestik berkontribusi terhadap kebijakan represif Hungaria dalam isu pengungsi dan migran dari Timur Tengah periode 2015-2019? Pertanyaan yang ada dalam tulisan ini mengarahkan artikel ini untuk melakukan analisis kebijakan yang dikeluarkan oleh Hungaria pada level domestik. Analisis ini akan melihat dinamikadomestik yang ada Hungaria yang difokuskan pada rentan waktu tahun 2015-2019, hal ini didasarkan bahwa dalam upaya untuk mengkonsolidiasikan dukungan masyarakat terhadap rezim yang berkuasa diperlukan sebuah isu yang mampu menunjukan kapabilitas rezim tersebut untuk memersatukan dan menciptakan stabilitas dalam negeri. Isu ini yang kemudian digunakan untuk menjamin keberlangsungan atau pencapaian kepentingan para elit 
domestik. Pemerintah Hungaria menjadikan isu pengungsi sebagai bagian dari upaya untuk memeroleh keuntungan politik dalam rangka melanggengkan rezim yang tengah berkuasa dengan legitimasi dari masyarakat Hungaria yang dibentuk melalui persepsi identitas nasional Viktor Orban, Dinamika politik domestik pada tahun 2015-2018 serta penguatan populisme dan ideologi sayap kanan.

\section{PEMBAHASAN}

\section{A. FAKTOR DOMESTIK DALAM PENGAMBILAN KEBIJAKAN.}

Penelitian mengenai kebijakan Hungaria terhadap isu pengungsi dan migran dapat dirujuk pada karya klasik Easton (1953) dimana terdiri atas tiga tahapan yakni input, proses dan output (kebijakan). Penelitian mengangkat permasalahan atas output (kebijakan) yang telah diambil dan diimplementasikan oleh pemerintah Hungaria terhadap pengungsi dan migran asal Timur Tengah yang datang ke negaranya. Kebijakan represif dalam menangani pengungsi dan migran yang diterapkan pemerintah Hungaria tidak sejalan dengan Konvensi 1951 dan Protokol 1967 mengenai Pengungsi. Oleh karena itu penelitian ini mencoba untuk melihat pada sisi input yang akan membentuk kebijakan represif Hungaria terhadap pengungsi dan migran. Input sendiri dapat dipahami sebagai sebuah momentum dimana tekanan sosial hadir kepada aktor politik (de Jesus, 2010). Pada tahapan awal ini pembuat kebijakan akan menentukan agenda-setting dengan memrioritaskan isu apa yang akan menjadi agenda. Dimana dalam proses pembuatan kebijakan yang terkait dengan isu internasional, pembuat kebijakan dipengaruhi baik oleh faktor internal (domestik) maupun faktor eksternal (internasional).

Bagi sebuah negara terdapat 3 level yang memengaruhi kebijakan yakni level individual, level struktur politik domestik dan level sistem internasional (Waltz, 1959). Level analisis ini memiliki kontribusi penting dalam memberikan fokus terhadap upaya untuk mencari alasan dibalik kebijakan represif Hungaria terhadap para pengungsi dan migran yang datang ke negaranya. Penelitian ini mengambil fokus untuk menganalisi pada level kedua, yakni level struktur domestik. Level ini dipilih karena perilaku subjektif dan struktur yang ada pada 
level domestik atau faktor internal memberikan kontribusi untuk memahami alasan dibalik kebijakan luar negeri dari sebuah negara (Schweller, 2018: 28. serta Firoozabadi dan Ashkeri, 2016: 96). Tekanan dalam struktur politik domestik dalam rangka pemenuhan kepentingan-kepentingan yang ada didalam negeri Hungaria memainkan peranan penting dalam membentuk kebijakan terhadap pengungsi dan migran dibandingkan dengan kepentingan yang harus dicapai pada tataran internasional.

Faktor domestik dapat tercemin dari kelompok kepentingan, kepentingan negara dan perilaku para elit politik (Snyder, 1991:22), dimana faktor tersebut akan menjadi tekanan terhadap pembuatan kebijakan represif dari Hungaria terhadap para pengungsi dan migran. Schweller (2014: 168) memberikan penjelasan bahwa terdapat kemungkinan dalam pengambilan kebijakan yang menjadi pemicu tindakan dan berperilaku yang berkecenderungan dipengaruhi oleh kondisi politik domestik, yang dalam hal ini kondisi politik domestik Hungaria yang didasarkan pada preferensi elit-elit politik di negara tersebut. Disisi lain Synder (1991: 1-2) memberikan penekanan pada isu keamanan nasional sebagai justifikasi bagi pengambilan kebijakan, kebijakan yang dihasilkan atas berbagai kompromi dari elit politik maupun kelompok kepentingan (power-politics, ekonomi dll). Kelompokkelompok ini dalam rangka mencapai kepentingannya menggunakan isu keamanan nasional sebagai upaya untuk melindungi atau mencapai kepentingan publik yang terkait dengan kelangsungan hidup masyarakat dan negara. Dengan demikian maka, isu pengungsi dan migran menjadi isu keamanan nasional yang harus segera ditangani dengan kebijakan-kebijakan yang ditujukan untuk mengeliminasi ancaman tersebut, dimana dalam hal ini adalah kebijakan yang bersifat represif.

\section{B. KEBIJAKAN HUNGARIA DALAM KRISIS PENGUNGSI DAN MIGRAN TAHUN 2015-2019.}

Tahun 2015 seiring dengan semakin berlarutnya konflik yang terjadi di Timur Tengah, khususnya Suriah membawa dampak terhadap meningkatnya pengungsi yang menuju ke negara Eropa. Hungaria menjadi gerbang bagi masuknya para pengungsi yang menggunakan jalur darat untuk menuju Jerman dan 
negara Eropa Utara (Skandinavia). Meskipun demikian, Hungaria mencegah bahkan mengusir para pengungsi dan migran tersebut untuk tidak masuk dan melintasi negaranya. Upaya Hungaria dalam mencegah dan mengusir para pengungsi dan migran ini diwujudkan melalui kebijakan yang sistematis oleh pemerintahan Viktor Orban. Juhaz (2017: 40) memaparkan kebijakan yang diambil oleh Viktor Orban dalam rangka menghadapi krisis pengungsi tersebut meliputi pembangunan pagar kawat berduri disepanjang perbatasan serta melakukan amademen terhadap Undang-Undang Pemberian Suaka, Hukum Kriminal dan Undang-Undang Prosedur Kriminal.

Pembangunan pagar dengan kawat berduri disepanjang perbatasan dengan Serbia merupakan cerminan keenganan Hungaria untuk menerima para pengungsi dan migran. Tidak sampai disana pagar tersebut kemudian dipasangi kawat berduri bahkan hingga dialiri listrik dalam rangka mencegah masuknya para pengungsi tersebut ke wilayah Hungaria. Pembangunan pagar ini menjadi prioritas dari pemerintah Hungaria yang kemudian menunjuk Kementrian Pertahanan sebagai penanggungjawab pembangunan tersebut. Dimana angkatan bersenjata Hungaria diturunkan untuk menyelesaikan pembangunan pagar disepanjang perbatasan bersama dengan pekerja sipil lainnya. Bahkan pada tahun 2016 Viktor Orban mengumumkan penguatan pagar perbatasan dengan sistem berlapis dalam rangka menghadapi tekanan gelombang pengungsi dan migran yang semakin meningkat.

Amandemen yang dilakukan oleh pemerintahan Viktor Orban membuat para pengungsi dan migran yang mengajukan diri sebagai pencari suaka harus melewati dua kali zona transit, dimana zona transit ini menyerupai tahanan. Para pengungsi dan migran tidak diperbolehkan meninggalkan Hungaria dalam beberapa bulan terkecuali kembali ke Serbia. Disamping itu jika aplikasi mereka ditolak mereka diharuskan untuk menetap selama beberapa bulan di Serbia untuk kemudian memasuki kembali Hungaria. Dengan demikian para pengungsi dan migran ini harus menunggu waktu yang cukup lama untuk memeroleh hak mereka bahkan untuk melanjutkan perjalanan ke negara tujuannya yakni Jerman maupun negara Eropa Utara. 
Amandemen terhadap hukum kriminal dan Undang-Undang Kriminal di Hungaria sebagai kebijakan pemerintah dalam menghadapi krisis pengungsi dan migran memberikan signifikansi terhadap penanganan masalah pengungsi dan migran oleh aparat yang terkait dengan imigrasi maupun kepolisian. Amandemen ini mengkriminalisasi pelintas batas yang dalam hal ini ditujukan terhadap pengungsi dan migran dengan sanksi penjara selama 8 tahun (Benkova, 2017: 2). Lebih jauh, kriminalisasi ini juga diterapkan kepada warga Hungaria serta pihak lain yang memberikan bantuan terhadap pengungsi dan migran untuk masuk ke wilayah Hungaria. Tidak hanya sampai disana, amandemen ini juga memberikan legitimasi bagi pihak kepolisian untuk menggunakan pendekatan keamanan (represif) dalam penanganan pengungsi dan migran, khususnya yang berada di wilayah perbatasan dengan Serbia (Amnesty International, 2015).

Kebijakan-kebijakan yang dikeluarkan oleh Hungaria tersebut dalam menangani pengungsi yang datang ke negaranya dikategorikan tindakan yang melanggar HAM dan hukum internasional termasuk adanya perubahan dalam kebijakan terhadap pencari suaka, serta kriminalisasi terhadap pelintas batas. Berbagai kecaman datang baik dari UE maupun komunitas internasional lainnya atas kebijakan yang dikeluarkan dalam menghadapi permasalahan pengungsi dan migran tersebut. Namun dalam hal ini pemerintah Hungaria tetap meyakini bahwa kebijakan yang diambil merupakan kebijakan terbaik dalam rangka memberikan rasa aman kepada masyarakat Hungaria dari ancaman para pendatang tersebut. Kebijakan ini yang kemudian menjadi fenomena untuk diangkat dalam tulisan ini dengan menganalisis latar belakang politik yang menjad setting dibalik kebijakan kontroversial dari Pemerintah Hungaria dibawah Perdana Menteri Viktor Orban terhadap para pengungsi dan migran tersebut.

\section{PERSEPSI VIKTOR ORBAN TERHADAP IDENTITAS NASIONAL HUNGARIA.}

Nasionalisme menjadi sebuah isu yang tidak lagi hanya dapat dipahami sebagai upaya pembentukan sebuah negara merdeka serta perjuangan untuk kebebasan namun juga sebagai upaya untuk membangun persamaan atas dasar 
identitas. Permasalahan yang kemudian mengemuka adalah bahwa nasionalisme yang diusung dalam konteks politik, senantiasa melahirkan politik identitas. Dengan demikian maka perbincangan mengenai nasionalisme memiliki kencenderungan untuk menghindarkan permasalahan identitas nasional dan kekuatan etnisitas dalam membentuk kebijakan (Kiss, 2000). Kondisi ini tidak dapat dilepaskan dari kekuatiran masuknya etno-nasionalismexenophobia, kencenderungan genosida dan pembentukan wilayah berbasis etnisitas dalam kebijakan yang dibuat. Meskipun demikian identitas nasional menjadi senjata ampuh dalam mengumpulkan dukungan terhadap suatu kebijakan dalam rangka menghadapi berbagai permasalahan seperti keamanan, perdagangan, imigrasi dan lain sebagainya.

Viktor Orban melihat identitas nasional sebagai gagasan untuk mewujudkan prioritas kebijakan persatuan nasionaldiantara masyarakat Hungaria. Gagasan ini menjadi dasar kebijakan untuk memberikan status kewarganegaraan bagi etnis Hungaria yang berada di luar negaranya (Deak, 2013: 154). Kebijakan ini sebagai komitmen untuk memberikan perlindungan terhadap keberadaan dari masyarakat Hungaria yang berada di luar negaranya agar tetap merasa menjadi bagian dari bangsa Hungaria. Kebijakan tersebut menunjukan komitmen dari politik patriotik yang didasarkan pada kepentingan bangsa Hungaria untuk memberikan perlindungan terhadap warga Hungaria yang menjadi minoritas di negara tetangga serta dalam rangka memertahankan kebanggaan sejarah Hungaria.

Bagi Viktor Orban, identitas nasional menjadi isu penting untuk diangkat seiring dengan upaya pemerintahannya dan Partai Fidesz untuk memerkuat kebanggaan sebagai masyarakat Hungaria. Viktor Orban dan Partai Fidesz senantiasa memosisikan diri sebagai penyelamat bagi Hungaria sebagai sebuah bangsa untuk dapat keluar dari kesulitan yang dialami pada abad ke 20 dan memertahankan masyarakatnya dari upaya untuk memecah belah maupun memengaruhi identitas nasional yang dimilikinya (Toomey, 2018: 97).

Identitas nasional Hungaria didasarkan pada nilai-nilai Kristen dalam masyarakat Hungaria kemudian diangkat oleh Viktor Orban sebagai warisan kebudayaan Hungaria. Nilai ini kemudian diwujudkan dalam bentuk penolakan 
terhadap pernikahan sesama jenis dimana dalam Undang-Undang Hungaria pernikahan hanya diakui antara pria dan wanita (Rydlinski, 2018: 98). Meskipun demikia, tidak dapat dipungkiri bahwa kondisi ini menunjukan adanya sentralitas secara politik yang dilakukan oleh pemerintahan Viktor Orban melalui nilai-nilai Kristen yang dianut oleh masyarakat Hungaria yang disematkan melalui gagasan identitas nasional.

Pada kasus Hungaria yang tengah menghadapi permasalahan pengungsi dan migran, Viktor Orban sebagai kepala pemerintahan yang berkuasa kemudian mengangkat gagasan identitas nasional kepada masyarakat identitas nasional untuk dihadapkan pada kedatangan pengungsi dan migran ke Hungaria. Dengan tujuan untuk membangun sebuah kesadaran atas kondisi oposisi biner mengenai "kita" sebagai masyarakat Hungaria dan "mereka" sebagai pendatang yakni para pengungsi dan migran. Oposisi biner yang tercipta akan membawa adanya ancaman yang berasal dari para pendatang yakni pengungsi dan migran dengan masyarakat Hungaria dengan identitas nasional yang terbangun sebelumnya. Keyakinan atas nilai Kristen ini yang digunakan oleh Viktor Orban untuk membangun nasionalisme dikalangan masyarakat Hungaria untuk menghadapi gelombang pengungsi dan migran yang datang ke negaranya.

Viktor Orban, bersama dengan negara lain yang menolak kehadiran pengungsi dan migran ini melihat dan meyakinkan masyarakat Hungaria bahwa para pengungsi dan migran yang datang akan membuat mereka kehilangan identitas dan budaya Kristen (Fatima, 2017). Kondisi ini tidak dapat dilepaskan dari identitas yang dibawa oleh para pengungsi dan migran yang berasal dari Timur Tengah dengan identitas Islam yang melekat pada diri mereka. Narasi yang kemudian dibangun adalah akan terjadinya perubahan identitas nasional dengan masuknya nilai-nilai yang dibawa oleh para pengungsi dan migran tersebut. Viktor Orban meyakini bahwa kedua nilai tersebut tidak dapat hidup berdampingan satu dengan yang lain, bahkan cenderung saling bertentangan dengan merujuk pada sejarah di masa perang salib. Melalui identitas nasional yang dibangun, Viktor Orban hadir sebagai pahlawan dan pelindung masyarakat Hungaria dengan kebijakan-kebijakan 
yang dibuat oleh pemerintahannya dalam menghadapi gelombang pengungsi dan migran tersebut.

Kebijakan-kebijakan represif yang kemudian dikeluarkan oleh Pemerintah Hungaria dibawah Viktor Orban merupakan bagian dari upaya memertahankan identitas nasional dari ancaman yang datang dari identitas yang dibawa oleh pengungsi dan migran tersebut ke negaranya. Dengan demikian, Pemenerintah Hungaria berharap memeroleh kepercayaan dari masyarakatnya yang telah terbangun ketakutannya terhadap "other" atau orang asing.

Krisis pengungsi dan migran yang terjadi pada tahun 2015 di Eropa dan Hungaria menjadi momentum bagi Viktor Orban untuk kembali memerkuat identitas nasional ditengah masyarakat. Melalui identitas nasional ini Viktor Orban tidak hanya berupaya untuk mengangkat citra diri dan partai Fidesz namun juga Hungaria sebagai negara yang menentang kebijakan quota pembagian beban pengungsi yang diberikan oleh UE. Dengan demikian, identitas nasional merupakan instrumen politik yang digunakan oleh Viktor Orban dalam kaitan dengan upaya memenangkan dukungan dari masyarakat Hungaria. Dukungan yang diberikan masyarakat Hungaria tidak hanya sebagai dasar legitimasi kekuasaan namun juga legitimasi untuk melakukan tindakan-tindakan represif terhadap pengungsi dan migran yang mencoba masuk ke Hungaria di tengah kecaman yang diberikan oleh masyarakat internasional.

\section{DINAMIKA POLITIK DOMESTIK HUNGARIA TAHUN 2015-2019}

Hungaria merupakan negara yang memiliki bentuk Republik Kesatuan dengan sistem pemerintahan parlementer, sistem politik yang digunakan adalah demokrasi. Sebagaimana negara lain dengan sistem parlementer Perdana Menteri Hungaria dipilih dan ditentukan oleh parlemen dalam rangka menjalankan tugas sebagai kepala pemerintahan dan menjalankan kewenangan eksekutif. Perdana Menteri Hungaria berasal dari partai yang memiliki kursi mayoritas di parlemen. Dengan demikian, partai yang menguasai mayoritas kursi di parlemen memiliki kuasa untuk membentuk pemerintahan sesuai dengan ideologi serta gagasangagasan yang dimiliki oleh partai penguasa. 
Dalam pemilu yang digelar pada tahun 2014, Fidesz kembali memenangkan pemilu, meskipun dengan persentase suara yang lebih rendah dari kemenangan pada pemilu sebelumnya. Penurunan elektabilitas ini merupakan dampak dari upaya pemerintah Hungaria untuk menerapkan pajak khusus terhadap internet. Sebuah kebijakan yang tentu tidak populer membuat popularitas pemerintahan Viktor Orban mengalami penurunan popularitas secara signifikan pada bulan November 2014. Kondisi ini tentu tidak menguntungkan bagi Viktor Orban dan Fidesz sebagai partai pengusungnya untuk memertahankan elektabilitasnya menghadapi pemilu berikutnya di tahun 2018. Diperlukan sebuah strategi dan momentum untuk mengembalikan popularitas pemerintahan Viktor Orban. Bagi Viktor Orban dan Fidesz maupun pihak oposisi sendiri gelombang pengungsi yang datang ke Eropa dilihat sebagai sebuah isu yang dapat dijadikan sebagai strategi serta momentum tepat untuk mendongkrak kembali kepercayaan masyarakat Hungaria atau menyerang lawan politiknya.

Pemerintahan Viktor Orban mengambil momentum ini dengan menggelar referendum kepada masyarakatnya dalam rangka kebijakan penerimaan pengungsi dan migran dengan merujuk pada kebijakan Uni Eropa. Meski menuai banyak kontroversi karena hasilnya dianggap tidak valid, namun kenyataannya hasil tersebut dijadikan sebagai legitimasi bagi Viktor Orban untuk mengimplementasikan berbagai kebijakan yang juga kontroversial terhadap para pengungsi dan migran tersebut. Pada tahun 2015 isu pengungsi dan migran ini terus menjadi komoditas pada semua ruang politik di Hungaria untuk mencapai tujuan pemerintah (Kekesi, 2017: 7). Kondisi ini tercermin dari pertarungan politik yang kemudian terjadi dengan memertemukan gagasan "nasionalisme" dan "antinasionalime" dengan menggunakan isu pengungsi dan migran. Terlebih isu ini menjadi hangat seiring dengan kedatangan pengungsi dan migran yang berasal dari Timur Tengah ke Hungaria dalam jumlah yang cukup banyak serta kebijakan quota yang diterapkan oleh UE untuk menerima pengungsi tersebut di negara-negara anggotanya. Disamping itu, Viktor Orban dan Fidesz pada tahun 2015 tengah berupaya untuk membendung upaya dari George Soros untuk membawa imigran yang berasal dari Afrika dan Asia ke Eropa, termasuk ke Hungaria. Upaya dapat 
dilihat dari besarnya anggaran yang mencapai lebih dari 100 Juta Euro yang diberikan kepada Partai Fidesz untuk meyakinkan para pemilihnya dan masyarakat Hungaria atas agenda tersebunyi dibalik rencana George Soros tersebut (Krezko dan Enyedi, 2018).

Keberadaan pengungsi dan migran di negaranya baik dalam rangka meminta aplikasi suaka maupun untuk transit, menjadikan Hungaria sebagai sorotan dari berbagai pihak, khususnya organisasi yang bergerak dalam bidang kemanusiaan. Pada ranah domestik pun, banyak masyarakat Hungaria yang menyatakan ketidaksetujuan dengan gagasan yang diangkat oleh Viktor Orban. Kondisi ini ditangkap sebagai momentum bagi partai oposisi untuk mendulang suara dari pemilih yang berpaling dari partai Fidesz. Dengan demikian pada periode 2015 hingga pemilihan umum tahun 2018, polarisasi politik khususnya mengenai penerimaan maupun penolakan terhadap pengungsi dan migran menjadi bagian dalam dinamika politik di Hungaria. Identitas nasional sebagai dasar nasionalisme menjadi senjata dari Viktor Orban dan Fidesz untuk memojokan lawan politiknya dengan melabeli mereka yang menjadi opsisi terhadap kebijakan yang ditujukan kepada pengungsi dan migran sebagai anti nasionalisme.

Viktor Orban menggunakan ancaman yang datang dari pengungsi dan migran serta keberadaan orang asing untuk menciptakan rasa takut diantara masyarakat. Rasa takut dalam masyarakat ini adalah upaya untuk tetap menjamin keberlangsungan dari kepemimpinan Viktor Orban dan dominasi Partai Fidesz di Hungaria. Strategi ini terbukti berhasil dengan diamankannya Kursi Perdana Menteri oleh Viktor Orban untuk ketiga kalinya serta dikuasainya 2/3 kursi di parlemen oleh Partai Fidesz pada bulan April 2018 (Timmer dan Docka-Filipek, 2018: 42). Kemenangan ini menjadi legitimasi bagi Pemerintahan Viktor Orban untuk membuat kebijakan yang dianggap "melindungi Hungaria dari ancaman orang asing" serta membungkam pihak-pihak yang menentang tujuan tersebut. Melalui kemenangan dalam pemilu tersebut Viktor Orban kemudian berupaya untuk mendesain permasalahan utama yang akan menjadi prioritas dalam pemerintahannya yakni terkait imigrasi dan keamanan nasional, dimana masyarakat 
Hungaria akan dapat memutuskan bahwa hanya mereka yang dapat dinggal di Hungaria dan siapa yang dapat tinggal bersama mereka di Hungaria (Walker, 2018).

\section{E. PARTAI FIDESZ: PENGUATAN POPULISME DAN IDEOLOGI SAYAP KANAN}

Fidesz merupakan partai politik yang memiliki haluan ideologi nasional konservatif serta dikenal sebagai partai populis sayap kanan. Nasional konservatif sendiri memiliki penekakan terhadap kepentingan nasional dan sangat menjunjung tinggi identitas etnis, gagasan ini sejalan dengan pemikiran Viktor Orban sebagai pemimpin partai ini terhadap identitas nasional yang dibangun ditengah masyarakat Hungaria. Sementara populis sayap kanan lebih merujuk pada posisi menentang keberadaan kelompok elitis dan berusaha untuk menyingkirkan berbagai hal yang akan mengancam eksistensi mereka. Saat dihadapkan dengan pengungsi dan migran serta kebijakan kuota penerimaan yang diberikan oleh UE, menjadi panggung bagi Fidesz untuk mengangkat gagasan konservatif yang digabungkan dengan populisme sayap kanan ditengah masyarakat Hungaria.

Fidesz sendiri menjadi instrumen dalam rangka menciptakan sistem "illiberal" dalam politik di Hungaria dimana dapat diraih dengan menciptakan tiga kondisi yakni, melalui sistem pemilihan umum, mengangkat kekecewaan atas kondisi yang terjadi pada periode sebelumnya serta adanya pemimpin kharismatik yang disematkan pada Viktor Orban (Krezko dan Enyedi, 2018). Kondisi kedua dan ketiga yang kemudian ingin diciptakan oleh Fidesz seiring dengan mengemukanya isu pengungsi dan migran di Hungaria. Fidesz dalam hal ini senantiasa melayangkan kritik terhadap kebijakan UE yang tidak memberikan keuntungan yang signifikan terhadap masyarakat Hungaria, terlebih dengan kuota relokasi pengungsi dan migran kepada negara anggotanya. Narasi yang dibangun adalah kekecewaan masyarakat Hungaria terhadap kebijakan EU khususnya terkait pengungsi dan migran dimana Fidesz menjadi yang terdepan dalam memerjuangkan kepentingan masyarakat Hungaria. Sementara Viktor Orban diposisikan sebagai tokoh kharismatik partai Fidesz yang menjadi penyelamat atau pelindung Hungaria dari gelombang pengungsi dan migran. 
Upaya Fidesz tersebut tentu memeroleh hambatan dari partai oposisi, dimana isu pengungsi dan migran ini pun kemudian digunakan oleh partai oposisi. Penderitaan yang dialami oleh para pengungsi dan migran dikapitalisasi oleh pihak oposisi untuk mendorong keterlibatan mereka dalam membangun gagasan mengenai kepentingan masyarakat pada level nasional. Partai oposisi melihat bahwa krisis migran yang merupakan dialektika dari partai Fidesz dibangun sebagai upaya dari pemerintah Hungaria untuk menciptakan musuh baik yang berasal dari dalam maupun dari luar dengan tujuan untuk stabilisasi kekuatan dan menciptakan suasana mencekam serta perpecahan sosial yang tidak sesuai dengan narasi Hungaria sebagai sebuah bangsa (Cantat, 2019: 195). Tidak hanya sampai disana, narasi mengenai permasalahan pengungsi ini juga diperluas kepada negara-negara yang ada di wilayah Eropa Tengah.

Bagi para politisi yang berada di negara (Visegrad Four) ${ }^{2}$ V4 termasuk didalamnya Hungaria, kesepakatan relokasi migran merupakan sebuah pemaksanaan agar masyarakat di negaranya menjadi masyarakat yang multireligius. Kekhawatiran akan masyarakat multi-relijius ini merujuk pada para pengungsi dan migran yang datang ke negaranya berasal dari Timur Tengah (beragama Islam) sehingga ada kecurigaan meningkatnya terorisme, dimana hal ini dapat menjadi pemicu Hungaria dan negara V4 lainnya untuk keluar dari Uni Eropa jika kesepakatan tersebut dijalankan oleh Komisi Eropa (Karolewski dan Benedikter, 2018: 41). Pandangan ini tidak dapat dilepaskan dari pengaruh partai sayap kanan yang ada di negara-negara tersebut. Fidesz melihat bahwa momentum ini merupakan sebuah kesempatan untuk memerkuat solidaritas diantara partai sayap kanan untuk menggaungkan populisme dalam menghadapi isu pengungsi dan migran di negara mereka masing-masing. Bagi Hungaria penolakan terhadap pengungsi merupakan sebuah mekanisme yang dapat digunakan untuk

\footnotetext{
2 Visegrad Four merupakan aliansi dari negara di kawasan Eropa Tengah yang beranggotakan Republik Ceko, Hungaria, Polandia dan Slovakia. Aliansi ini didasarkan pada upaya penguatan kerjasama yang didasarkan pada kepentingan bersama. Keempat negara tersebut mengidentifikasikan dari memiliki persamaan kebudayaan, nilai dan akar tradisi religius yang ingin dilestarikan dan diperkuat.
} 
memosisikan dirinya sebagai negara dengan suara sayap kanan yang berpengaruh dikawasan (Pradana, 2018).

\section{KESIMPULAN}

Berdasarkan pembahasan yang telah dilakukan, kebijakan-kebijakan represif dan tidak berpihak pada hak pengungsi seperti yang diamanatkan dalam Konvensi 1951 dan Protokol 1967 oleh pemerintah Hungaria didorong oleh faktor domestik khususnya terkait dinamika dan strategi politik para elit. Faktor domestik pertama terkait dengan gagasan identitas nasional dari Perdana Menteri Hungaria Viktor Orban. Gagasan yang berupaya untuk memerkuat identitas bangsa Hungaria dari sisi etnisitas, budaya dan nilai agama Kristen ini dihadapkan dalam oposisi biner dengan identitas yang dibawa oleh pengungsi dan migran yang berasal dari Timur Tengah sehingga dikuatirkan menjadi ancaman terhadap identitas nasional Hungaria. Faktor kedua terkait dengan dinamika politik yang terjadi di Hungaria, khususnya terkait dengan pengalihan isu serta upaya untuk memerkuat posisi partai berkuasa dan pemerintah melalui keberadaan ancaman yang berasal dari pengungsi dan migran sebagai strategi untuk mengamankan kebijakan dan legitimasi pemerintah serta memenangkan pemilu yang akan diselenggarakan. Terakhir adalah penguatan ideologi sayap kanan serta populisme yang diangkat oleh Partai Fidesz untuk bersaing dengan partai opsisi sebagai rivalnya. Disamping itu Fidesz juga ingin mengukuhkan eksistensi dirinya sebagai kiblat dari haluan sayap kanan di Eropa Tengah khususnya saat berhadapan dengan kebijakan UE mengenai pengungsi dan migran.

Melihat kondisi domestik dalam pembuatan kebijakan di Hungaria dalam periode yang cukup panjang sehingga hanya memberikan penggambaran dan analisis secara umum terhadap faktor-faktor domestik tersebut. Penelitian ini tidak dapat melihat dinamika politik yang senantiasa menjadi warna dalam pengambilan kebijakan-kebijakan kontroversial pada saat menjelang pemilu.

Tulisan selanjutnya setelah tulisan ini terbit diharapkan dapat memotret dinamika yang terjadi dalam pengambilan kebijakan baik di Hungaria atau di negara lain dengan mengambil momentum saat sebuah pemerintahan maupun partai 
berkuasa menghadapi pemilu. Momentum ini menjadi menarik karena kebijakankebijakan yang diambil lebih pada pertimbangan strategi politik dibandingkan dengan kepentingan maupun kebutuhan dari masyarakat dalam jangka panjang.

\section{DAFTAR PUSTAKA}

Amnesty International. 2015. Fenced Out Hungary`s Violations of The Right of Refugees and Migrants. London: Amnesty International Publications.

Benkova, Livia. 2017. Europe `s Response to the Migration Crisis, Austria Institut Fur Europea-Und Sicherheitpolitik, Focus No.3 hlm 1-4.

Cantat, Celline. 2019. Governing Migrants and Refugees in Hungary: Politics of Spectacle, Negligence and Solidarity in Securitising Statedalam Hinger, Sophie dan Schweitzer, Reinhard. Politics of (Dis) Integration, Cham: Springer.

De Jesus, Anderson Macedo. 2010. Policy-Making Process and Interest Group: How do Local Government Association Influence Policy Outcome in Brazin and Netherland?Brazilian Political Science Review, Vol. 4 No.1 hlm 69-101.

Deak, Andras. 2013. Hungarian Dances - The Origin and the Future of Viktor Orban's Revolution, Lithuanian Annual Strategic Review, Vol. 11 No.1 hlm 145-168.

Easton, David. 1953. The Political System: Alnquiry into the State Political Science. New York: Alfred A Knopf.

Fatima, Zobi. 2017. Syrian Refugees in Europe: Responses of The EU and Member State, Journal of European Studies, Vol.33 No.2, hlm 77-90.

Firoozabadi, J.D dan Ashkeri, M.Z. 2016. Neo-Classical Realism in International Relations, Asian Social Science, Vol.12 No.6 hlm 95-99.

Juhaz, Kriztina. 2017. Assesing Hungary`s Stance on Migration and Asylum in Light of European and Hungarian Migration Strategis, Politics in Central Europe, Vol. 13 No. 1, hlm 35-54.

Karolewski, Ireneuz Pawel dan Benedikter, Roland. 2018. Europe`s Migration Predicament: The European Union`s Refugees`Relocation Scheme versus the Defiant Central Eastern EuropeanVisegard Group", Journal of Inter Regional Studies: Regional and Global Perspective, Vol. 1 hlm 40-53. 
Kekesi, Mark Zoltan. 2017. Hungary: Migration and the Policy of Closed Border, Briefing PaperNo.18. Praha: Association for International Affairs (AMO).

Kiss, L.J. 2000. Nation and Integration at the Turn of Millenium: Duality of Hungary`s Foreign Policy, Foreign Policy Review, Vol. 6 hlm 82-102.

Kreko, Peter dan Enyedi, Zsolt. 2018. Orban`s Laboratory of Illiberalism, Journal of Democracy, Vol. 29 No. 3 hlm 39-51.

Pradana. Aldoreza. 2018. National Identity: identity Politics in Hungary`s Refugee Influx 2015, ISS Brief No. 3.

Rydlinski, Bartosz M. 2018. Viktor Orban - First Amnong Illiberal? Hungarian and Polish StepTowardPopulist Democracy, On-Line Journal Modelling the New Europe, No.26 hlm 95-107.

Sainz-Pardo, P.V. 2002. The Contemporary Relevance of the 1951 Convention Relating to the Status of Refugees, The International Journal of Human Right, Vol. 6 No. 2 hlm 23-34.

Schweller, Randall L. 2018. The Opposite but Commpatible Nationalism: A Neocalssical Realist Approach to the Future of US-Tiongkok Relations, The Chinese Joirnal of International Politics, Vol. 11 No. 1 hlm 23-48.

Synder, Jack. 1991. Myth of Empire: Domestic Politics and International Ambition, New York: Cornell University Press.

Szoke, Laszlo. 1992. Hungarian Perspective on Emigration and Immigration in the New European Architecture, International Migration Review, Vol.26 No.2 (Special Issue: The New Europe and International Migration) hlm 305323.

Timmer, Andria D. dan Docka-Filipek, Danielle. 2018. Enemies of the Nations: Understanding the Hungarian State's Relationship to Humanitarian NGO `s, Journal of International and Global Studies, Vol. 9 No. 2 hlm 4157.

Toomey, Michael. 2018. History, Nationalism and Democracy: Myth and Narrative in Viktor Orban`s Illiberal Hungary, New Perspective, Vol. 26 No.1 hlm 87-108.

United Nations High Commissioner for Refugees. 2015. State Parties to the 1951 Convention Relating to the Status of Refugees and the 1967 Protocol. Diakses dari https://www.unhcr.org/protection/basic/3b73b0d63/statesparties-1951-convention-its-1967-protocol.html 
Walker, Shaun. 2018. "Orban Election Victory Gives us Mandate to Pass 'Stop Soros Laws"”, The Guardian, 10 April 2018, diakses 15 Agustus 2020. www.theguardian.com/world/2018/apr/10/orban-election-victory-givesus-mandate-to-pass-stop-soros-laws

Waltz, Kenneth. 1959. Man, the State and War: A Theoritical Analysis. New York: Columbia University Press. 